Article

\title{
Preparation and in Vitro Bioactivity of Micron-sized Bioactive Glass Particles Using Spray Drying Method
}

\author{
Yu-Jen Chou ${ }^{1}$, Chih-Wei Hsiao ${ }^{2}$, Nien-Ti Tsou $\left.{ }^{3}{ }^{(}\right)$, Meng-Huang $W_{u}{ }^{4,5}\left(\mathbb{D}\right.$ and Shao-Ju Shih ${ }^{2, *(D)}$ \\ 1 Department of Materials, University of Oxford, Oxford OX1 3PH, UK; yu-jen.chou@materials.ox.ac.uk \\ 2 Department of Materials Science and Engineering, National Taiwan University of Science and Technology, \\ No. 43, Sec. 4, Keelung Road, Taipei 10607, Taiwan; martin811024@gmail.com \\ 3 Department of Materials Science and Engineering, National Chiao Tung University, No. 1001, Tahsueh Road, \\ HsinChu 300, Taiwan; tsounienti@nctu.edu.tw \\ 4 Department of Orthopaedics, School of Medicine, College of Medicine, Taipei Medical University, \\ Taipei 11031, Taiwan; maxwutmu@gmail.com \\ 5 Department of Orthopedics, Taipei Medical University Hospital, Taipei 110, Taiwan \\ * Correspondence: shao-ju.shih@mail.ntust.edu.tw; Tel.: +886-2-2730-3716
}

Received: 26 October 2018; Accepted: 17 December 2018; Published: 21 December 2018

\begin{abstract}
In recent years, bioactive glasses (BGs) have attracted enormous attention with their superior bioactivity, non-toxicity and degradability. Owing to their properties, they have been applied in various biological applications. In the present work, we demonstrated that micron-sized BGs can be prepared with a spray drying method. This technique offers the advantages of low contamination and the ability of mass production, in contrast to the two major synthetic methods, conventional glass-melting and sol-gel, previously used for preparation of BGs. Characterizations of phase composition, morphology and specific surface area of spray dried BG powders were carried out and bioactivity was examined in vitro with respect to the ability to form a hydroxyapatite layer on the surface of the particles after they were immersed in simulated body fluid.
\end{abstract}

Keywords: bioactive glass; spray drying method; morphology; scanning electron microscopy

\section{Introduction}

Bioactive glasses (BGs) have attracted considerable attention since they was first developed by Hench et al. [1] in 1969. Various studies have demonstrated that when BGs are implanted into human body, layers of hydroxyapatite (HA), constituting the main mineral component of human bones, are formed on the surface of BGs [2-4]. These HA layers can chemically bond to human bones, which reduces rejection and inflammation $[5,6]$. Owing to properties such as bioactivity, non-toxicity and degradability, BGs have been applied in various biological applications such as toothpaste fillers [7], bone implants [8], drug carriers [9], and radioisotope vectors [10,11].

The first BG reported by Hench et al. [12] was fabricated by a conventional glass melting process; the process involved melting the raw precursors at high temperatures of $1250-1400{ }^{\circ} \mathrm{C}$ and casting the melts into bulk implants. However, the required high temperatures lead to disadvantages, such as high cost of energy consumption and platinum crucibles [13], partial crystallization due to different melting points and also potential contamination during grinding and sieving [14]. As BGs are fabricated for medical use, contamination must be avoided and purity must be assured. To avoid the disadvantages of the conventional glass melting process, Li et al. [14] synthesized BGs using a sol-gel method in 1991, which subsequently became one of the most popular BG fabrication methods, due to its lower heat treatment temperature (around $600^{\circ} \mathrm{C}$ ) and chemical flexibility (better control of the product's properties). In addition, by adding templates or surfactants, different morphologies can be prepared, 
including solid, hollow or mesoporous structures. For example, Yan et al. [15] used a tri-block surfactant to successfully synthesize a well-ordered mesoporous bioactive glass in 2004. Although the sol-gel method has been widely used for BG fabrication, the overall process follows a batch process that is, it is difficult to adapt to mass production, which usually requires several steps, some of which need long periods of time, up to $4-7$ days [16].

Spray pyrolysis offers the advantages of both processes described above; it is suitable for mass production, operates lower temperature of around $500-600{ }^{\circ} \mathrm{C}$ and produces high purity BGs within a period of 1-2 days [17]. The process involves dissolving the precursor ingredients in a solvent to form a precursor solution, which is then atomized into fine droplets using ultrasound and introduced into a tube furnace to undergo stages of solvent evaporation, solute precipitation and precursor decomposition [18]. Synthesized BG particles are then collected in a high voltage electrostatic deposition system located after the furnace.

However, owing to the nature of the ultrasonic atomizer, particle sizes of spray pyrolyzed BG lay around the sub-micron (300-800 nm) range [17-19]. This limits its applications, such as dermal fillings [20] and radioisotope vectors [10,11], which require a particle size up to few microns. Studies have shown that microspheres with larger particle size could survive the ingestion process of phagocytosis [20], while the mechanical properties can also be controlled by the size effects [21,22]. In contrast, the spray drying method is a widely applied manufacturing process which uses the aerosol phase to dry particles [23]. It is a well-establish technique that has been used for over a century in the fields of pharmaceuticals, polymers and ceramics [24]. Yet, although some authors have already produced BG with spray drying method [25,26], the particle sizes reported are only within $1 \mu \mathrm{m}$, which is still too small for the above applications.

Therefore, in this study, we aimed for the preparation of micron-sized BG powders of up to $20 \mu \mathrm{m}$ using the spray drying method instead of spray pyrolysis. Three common compositions of $58 \mathrm{~S}, 68 \mathrm{~S}$ and $76 \mathrm{~S}$ were chosen for a fair comparison. Characterizations of phase composition, surface structure, inner structure and specific surface area of BG powders were obtained using X-ray diffraction (XRD), scanning electron microscopy (SEM), focused ion beam (FIB) and nitrogen adsorption/ desorption isotherms. At last, the bioactive tests were carried out and the amount of HA phase characterized using XRD.

\section{Materials and Methods}

\subsection{Synthesis}

The BG powders were synthesized using spray drying method based on three most common compositions of $58 \mathrm{~S}\left(60 \mathrm{~mol} \% \mathrm{SiO}_{2}, 36 \mathrm{~mol} \% \mathrm{CaO}\right.$, and $\left.4 \mathrm{~mol} \% \mathrm{P}_{2} \mathrm{O}_{5}\right), 68 \mathrm{~S}\left(70 \mathrm{~mol} \% \mathrm{SiO}_{2}, 26 \mathrm{~mol} \%\right.$ $\mathrm{CaO}$, and $\left.4 \mathrm{~mol} \% \mathrm{P}_{2} \mathrm{O}_{5}\right)$, and $76 \mathrm{~S}\left(80 \mathrm{~mol} \% \mathrm{SiO}_{2}, 16 \mathrm{~mol} \% \mathrm{CaO}\right.$, and $\left.4 \mathrm{~mol} \% \mathrm{P}_{2} \mathrm{O}_{5}\right)$. By using tetraethyl orthosilicate (TEOS, $\mathrm{Si}\left(\mathrm{OC}_{2} \mathrm{H}_{5}\right)_{4}, 99.9 \mathrm{wt} \%$, Showa, Tokyo, Japan), calcium nitrate tetrahydrate (CN, $\mathrm{Ca}\left(\mathrm{NO}_{3}\right)_{2} \cdot 4 \mathrm{H}_{2} \mathrm{O}, 98.5 \mathrm{wt} \%$, Showa, Tokyo, Japan), and triethyl phosphate (TEP, $\left(\mathrm{C}_{2} \mathrm{H}_{5}\right)_{3} \mathrm{PO}_{4}, 99.0 \mathrm{wt} \%$, Alfa Aesar, Heysham, UK) as the source of $\mathrm{Si}$, $\mathrm{Ca}$ and $\mathrm{P}$, precursor solutions of various $\mathrm{BG}$ powders were prepared by dissolving TEOS, CN and TEP in $10.0 \mathrm{~g}$ of $0.5 \mathrm{M} \mathrm{HCl}$ and $360.0 \mathrm{~g}$ of ethanol based on their given $\mathrm{Si}, \mathrm{Ca}$ and $\mathrm{P}$ ratios. All precursor solutions were stirred at room temperature for $4 \mathrm{~h}$ to achieve homogeneity. For the spray drying process, the final precursor solutions were diluted with $1 \mathrm{~L}$ deionized water with concentration of $1.8 \mathrm{M}$ and dispersed into fine droplets using a high-speed rotating disc at 20,000 rpm, with flow rate around $50 \mathrm{~mL} / \mathrm{min}$, into the spray dryer machine (SD DD-03, IDTA machinery Co., New Taipei, Taiwan), with the hot chamber set at $200{ }^{\circ} \mathrm{C}$ to form BG powders. The resulting dried BG powders were collected in a drying tube and calcined at $600{ }^{\circ} \mathrm{C}$ for $1 \mathrm{~h}$ to form the final products. Finally, the BG powders were washed by $1 \mathrm{M}$ nitric acid to eliminate any impurity and un-reacted species. Note that following the procedure as described above, a precursor solution of $1 \mathrm{~L}$ can yield BG powder around $100 \mathrm{~g}$, corresponding to a yield of up to $90 \%$. 


\subsection{Structural Characterization}

The phase compositions of BG powders were obtained using a X-ray diffractometer (XRD, D2 Phaser, Bruker, Karlsruhe, Germany) with Ni-filtered $\mathrm{Cu} K \alpha$ radiation using collection angles ranging from 10 to $80^{\circ}$. Next, the surface structure was examined using a field-emission scanning electron microscope (SEM, JSM-6500F, JEOL, Tokyo, Japan) while another SEM equipped with focused ion beam (FIB, Quanta 3D FEG, FEI, Oregon, USA) was used to prepare the cross section specimen for the observation of the inner structure. Statistical measurements of particle size distributions and average particle sizes were measured by sampling more than 200 particles with a couple of SEM images Meanwhile, average pore sizes was computed by measuring more than 200 pores from the FIB cross section images. Also, atomic compositions were obtained using energy dispersive spectroscopy (EDS, X-Max $50 \mathrm{~mm}^{2}$, Oxford Instrument, High Wycombe, UK). In addition, the Brunauer-Emmett-Teller (BET) nitrogen adsorption method was used to analyze the specific surface areas of the BG powders. The nitrogen adsorption and desorption isotherms were obtained at $-196{ }^{\circ} \mathrm{C}$ on a constant-volume adsorption apparatus (Novatouch LX2, Quantachrome Instruments, Boynton Beach, FL, USA). As-prepared specimens were degassed at $150{ }^{\circ} \mathrm{C}$ for $3 \mathrm{~h}$ before the measurements.

\subsection{Bioactivity Test}

The in vitro bioactivity tests of all BG powders were carried out by immersing the powders in simulated body fluid (SBF) [27] with a solid to liquid ratio of $1 \mathrm{mg}$ to $5 \mathrm{~mL}$. Each specimen was held at $37^{\circ} \mathrm{C}$ for $12 \mathrm{~h}$ and washed with acetone and deionized water before drying at room temperature for one day. XRD was used to observe the phase information of HA to confirm the HA formation for the bioactivity.

\section{Results}

\subsection{Phase Composition}

Figure 1 shows XRD patterns of 58S, 68S and 76S BG powders prepared by spray drying method. First, for the 58S, the XRD pattern show the absence of any crystalline peak, with only a broad band existing between $15-35^{\circ}$, which suggests that the structure of $58 \mathrm{~S}$ BG powder is amorphous. Then, BG powders of $68 \mathrm{~S}$ and $76 \mathrm{~S}$ reveal the similar XRD patterns. Therefore, the result indicates that all spray dried BG powders were prepared successfully with glassy phase.

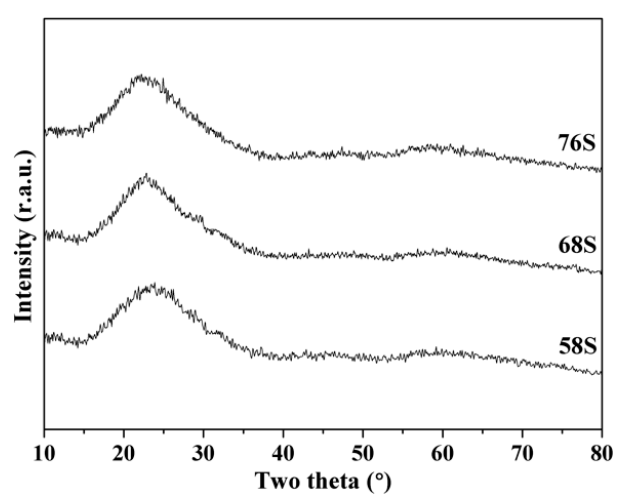

Figure 1. X-ray diffraction (XRD) patterns of spray dried 58S, $68 \mathrm{~S}$ and $76 \mathrm{~S}$ bioactive glass (BG) powders.

\subsection{Morphology and Composition}

The surface structures and inner structures of spray dried 58S, 68S, and 76S BG powders were examined to obtain the particle morphologies, and the corresponding results are shown below. Initially, Figure 2 shows the surface structure information of all spray dried powders with insets of particles at higher magnification. It can be seen from Figure 2a that the 58S BG powder exhibits the spherical 
shape which is the typical spray dried shape [23]. Meanwhile, it can also be seen that the surfaces of the particle are rough instead of smooth. This is due to the shell formation and buckling phenomenon happened during the particle formation stage [28]. In addition, 68S and 76S BG powders as shown in Figure $2 b, c$ reveal the same morphology but more severe rough surfaces.
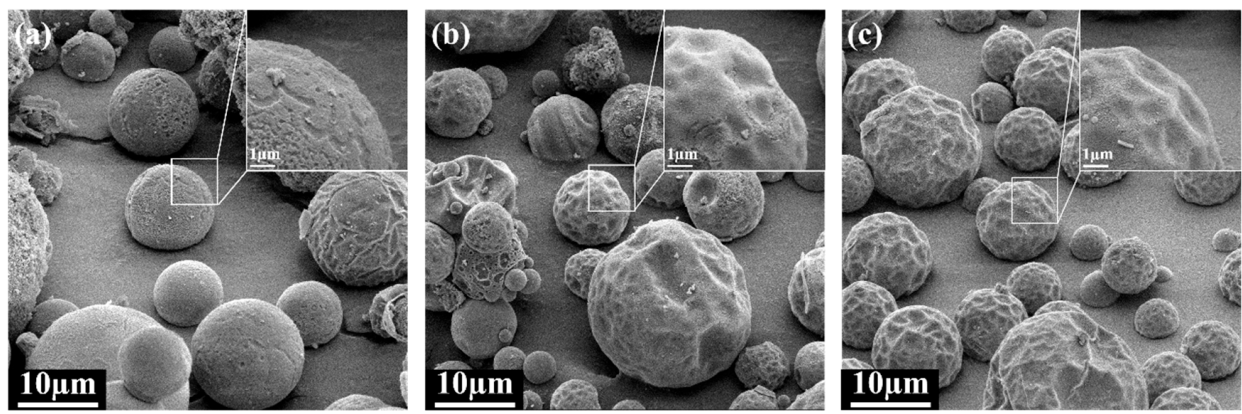

Figure 2. Scanning electron microscopy (SEM) images of spray dried (a) 58S; (b) 68S; and (c) 76S BG powders with insets of their surfaces captured at higher magnification.

Next, owing to the particle formation mechanism of the spray drying method, inhomogeneous morphologies have been discussed in previous studies [23-29]. Therefore, for obtaining particle morphology, the inner structure is required to verify with the surface structure for the correct particle morphology; for example, both hollow particles and solid particles exhibit the same surface structures [30]. Commonly, transmission electron microscopy (TEM) was used to collect information on the inner structure. However, based on the SEM images shown in Figure 2, particle sizes of all spray dried BG powders range around 2-20 $\mu \mathrm{m}$. Due to the huge particle sizes of BG powders, the particles might not be electron transparent in the TEM. Therefore, inner structures of all BG powders were examined using FIB-prepared cross section particles instead of TEM. Figure 3 shows the SEM images of FIB-prepared cross section particles with insets of their inner structures. With examination of more than 20 particles among each BG powder, the results show that all spray dried BG powders exhibit either solid (Figure $3 \mathrm{a}-\mathrm{c}$ ) or porous (Figure $3 \mathrm{~d}-\mathrm{f}$ ) inner structures.
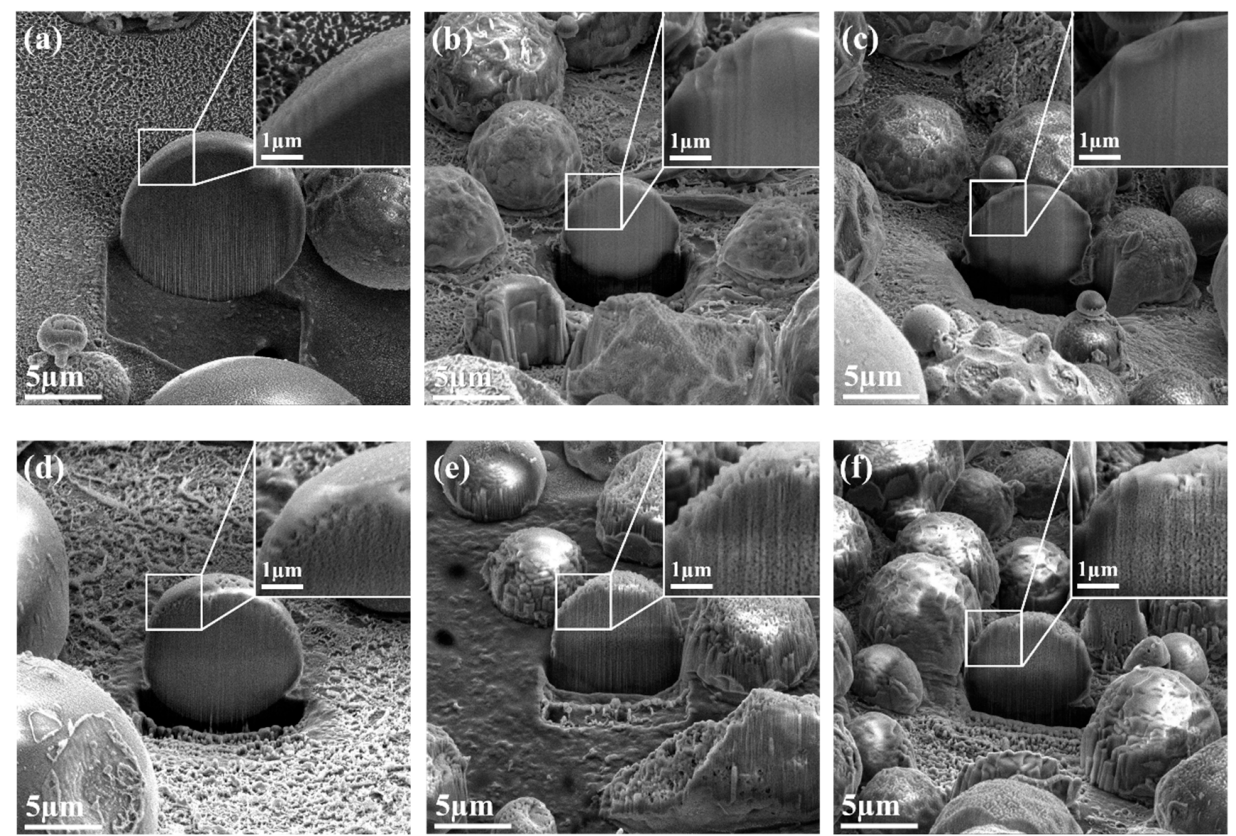

Figure 3. SEM images of focused ion beam (FIB)-prepared cross section particles showing solid and porous structure of (a,d) 58S; (b,e) 68S; and (c,f) 76S BG powders with insets of their inner structure captured at higher magnification. 

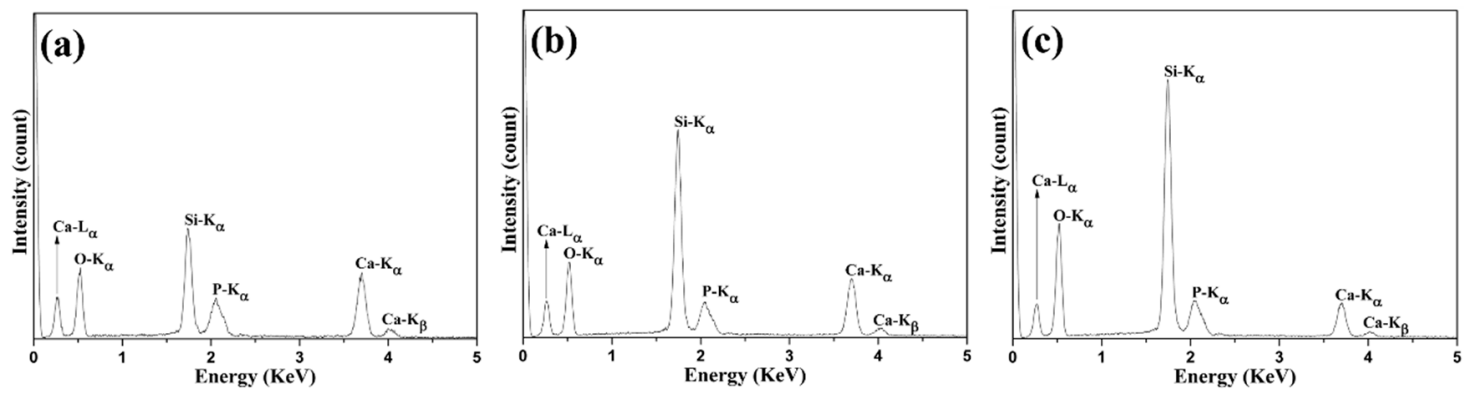

Figure 4. Energy dispersive spectroscopy (EDS) spectra of spray dried (a) 58S; (b) 68S; and (c) 76S BG powders.

Elemental analysis of all BG powders was carried out using EDS as shown in Figure 4. It can be seen from the graphs that all spectra have peaks at 0.52, 1.76, 2.05 and $3.69 \mathrm{KeV}$ which correspond to $\mathrm{O}-\mathrm{K} \alpha$, Si-K $\alpha, \mathrm{P}-\mathrm{K} \alpha$, and Ca-K $\alpha$ edges, respectively. In addition, an increasing trend of Si-K $\alpha$ edge can be observed from 58S, 68S to 76S, as well as a decreasing trend of Ca-K $\alpha$ edge. Moreover, Table 1 shows the atomic compositions derived from the EDS spectra. The result shows that all BG powders exhibit around $10 \mathrm{~mol} \%$ of $\mathrm{P}$ with Si ratio of 52,64 and $74 \mathrm{~mol} \%$ for $58 \mathrm{~S}, 68 \mathrm{~S}$ and $76 \mathrm{~S}$ BG powders, respectively. Indicating the successful synthesis of BG powders based on their given composition.

Table 1. Atomic compositions of 58S, $68 \mathrm{~S}$ and $76 \mathrm{~S}$ BG powders derived from EDS spectra.

\begin{tabular}{cccc}
\hline Specimen & Si & Ca & P \\
\hline $58 \mathrm{~S}$ & $52.47 \pm 2.26$ & $37.71 \pm 1.62$ & $9.81 \pm 0.65$ \\
$68 \mathrm{~S}$ & $63.64 \pm 3.09$ & $26.68 \pm 3.90$ & $9.68 \pm 1.15$ \\
$76 \mathrm{~S}$ & $74.18 \pm 0.90$ & $16.33 \pm 1.51$ & $9.49 \pm 0.83$ \\
\hline
\end{tabular}

\subsection{Particle Size, Pore Size and Specific Surface area}

Based on the SEM images shown in Figure 2, statistical measurement of the particle size distributions of all spray dried BG powders were calculated and shown in Figure 5. The graphs indicate that particle sizes of all BG powders exhibit a normal distribution, with insets of $d_{50}=8.5,8.0$ and $7.7 \mu \mathrm{m}$ for $58 \mathrm{~S}, 68 \mathrm{~S}$ and $76 \mathrm{~S}$ BG powders. The average sizes and the corresponding deviations were computed as $8.8 \pm 3.5,6.4 \pm 4.2$, and $5.9 \pm 3.5 \mu \mathrm{m}$ for $58 \mathrm{~S}, 68 \mathrm{~S}$ and $76 \mathrm{~S}$ BG powders. In addition, average pore sizes of all BG powders were measured as $61 \pm 10,68 \pm 12$ and $65 \pm 8 \mathrm{~nm}$. At last, BET measurement revealed that the specific surface areas of the $58 \mathrm{~S}, 68 \mathrm{~S}$, and $76 \mathrm{~S}$ BG powders were $39.1 \pm 1.9,21.9 \pm 0.5$ and $5.9 \pm 0.3 \mathrm{~m}^{2} / \mathrm{g}$, respectively.
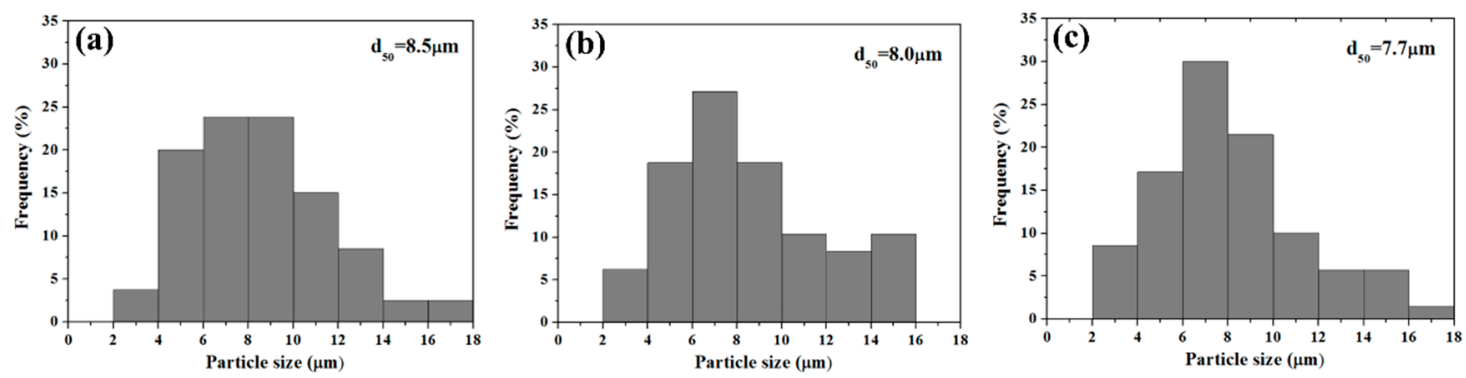

Figure 5. Particle size distributions of spray dried (a) 58S; (b) 68S; and (c) 76S BG powders.

\subsection{In Vitro Bioactivity}

For the in vitro bioactivity tests, Figure 6 shows the XRD patterns of $58 \mathrm{~S}, 68 \mathrm{~S}$ and $76 \mathrm{~S}$ bioactive glasses after immersing in SBF for $12 \mathrm{~h}$. Compared to XRD patterns of as-prepared BG powders shown 
in Figure 1, diffraction peaks of (211) and (112) peaks of HA (JCPDS No.84-1198) were observed in all BG powders. To compare the bioactivity of each specimen, background subtraction was performed on each XRD pattern and Figure 7 plots the intensities of (112) peak of HA as a function of $\mathrm{SiO}_{2}$ concentration. The graph shows that the intensities of HA peak of 58S, 68S and 76S are 550, 400 and 380 counts, respectively.

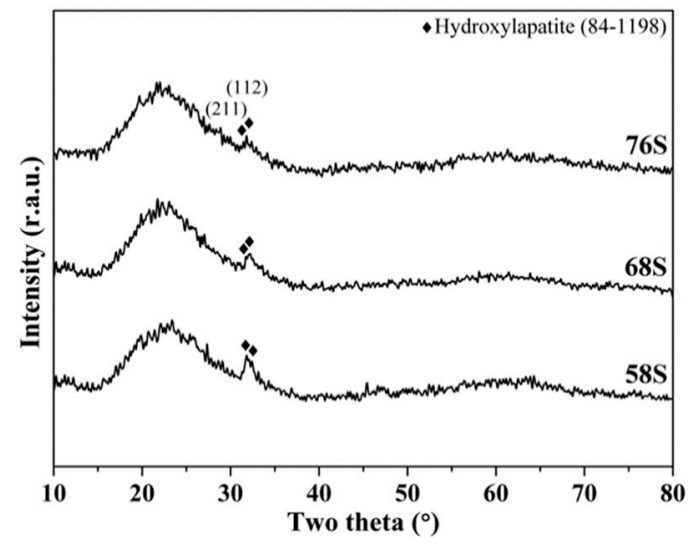

Figure 6. XRD patterns of 58S, 68S, and 76S BG powders soaked in simulated body fluid (SBF) for $12 \mathrm{~h}$.

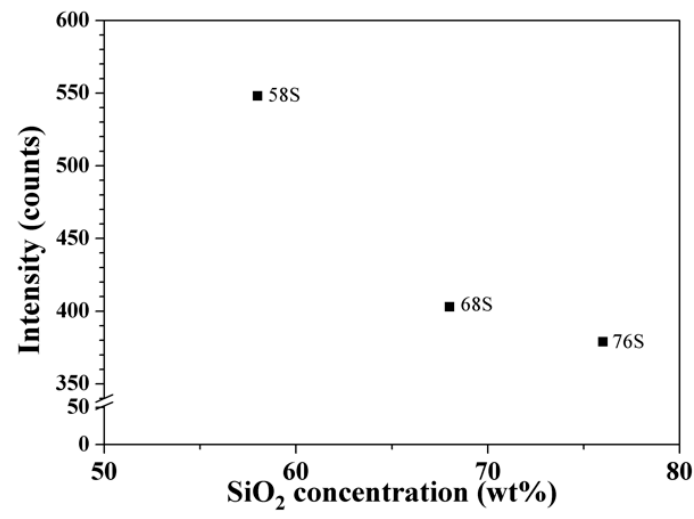

Figure 7. Intensities of hydroxyapatite (HA) (112) peak as a function of $\mathrm{SiO}_{2}$ concentration.

\section{Discussion}

First, based on the SEM images of as-prepared BG powders shown in Figure 2, it has been demonstrated that the particle morphology is spherical for all spray dried BG powders. This is due to the typical particle formation mechanism of spray drying method [31], similar to the "one-particle-per-drop" mechanism of spray pyrolysis [18]. Moreover, it can be seen from the FIB-prepared BG powders shown in Figure 3 that all BG powders exhibit solid or porous inner structures. During spray drying, hollow particles are often obtained. However, in this study, a low Peclet number in combination with a high solubility of the solutes could result in the formation of solid particles [29]. In addition, the porous structure is possibly formed due to the decomposition of the remaining solvent (e.g. $\mathrm{NO}_{3}{ }^{-}$) during the calcination process.

For the particle size distribution, histograms shown in Figure 5 suggest that all BG powders exhibit normal distributions with $\mathrm{d}_{50}$ around $8 \mu \mathrm{m}$. This is owing to the nature of droplet distribution controlled by the high-speed rotating disc. In addition, the average particle sizes of BG powders are computed as $8.8 \pm 3.5,6.4 \pm 4.2$ and $5.9 \pm 3.5 \mu \mathrm{m}$ for $58 \mathrm{~S}, 68 \mathrm{~S}$ and $76 \mathrm{~S}$ BG powders, respectively. Meanwhile, it also shows that the particle size of spray dried BG powders is about 10 times bigger than the particles size of spray pyrolyzed BG powders (300-800 nm) [17-19]. However, owing to the distribution of droplet sizes, the average particle sizes still present standard deviations around $50 \%$ similar to the BG particles synthesized using spray pyrolysis [32]. 
The specific surface areas were measured using BET and showed that all BG powders have surface areas ranging from 6 to $40 \mathrm{~m}^{2} / \mathrm{g}$. Meanwhile, with the density of $2.6 \mathrm{~g} / \mathrm{cm}^{3}$ for $45 \mathrm{~S} 5$ Bioglass ${ }^{\circledR}$ [33], the theoretical surface area of a BG particle with size of $8 \mu \mathrm{m}$ can be computed as $\sim 0.3 \mathrm{~m}^{2} / \mathrm{g}$. These results show an increased surface areas of 20 to 100 times as compared to the calculated values, which is due to internal porosity. With more than $20 \mathrm{FIB}$ cross section particles examined, the proportions of porous particles found are $85 \%, 50 \%$ and $20 \%$ for $58 \mathrm{~S}, 68 \mathrm{~S}$ and $76 \mathrm{~S}$ BG powders, respectively, which shows the same trend as the measured surface areas.

Finally, the bioactivity tests were carried out by immersing each specimen in SBF. Since the bioactivity of the glasses is directly related to the growth rates of HA, XRD patterns shown in Figure 6 were used to observe the formation of HA. The results show that all spray dried BG powders form HA phases of (211) and (122) after immersion in SBF for 12h. In addition, by performing background subtractions to the XRD patterns, Figure 7 plots the intensities of (112) reflection of HA as a function of $\mathrm{SiO}_{2}$ concentration. The graph provides a comparison of the bioactivity of each specimen, indicating the order of bioactivity is $58 \mathrm{~S}>68 \mathrm{~S}>76 \mathrm{~S}$.

\section{Conclusions}

In this study, micron-sized BG powders with compositions of 58S, $68 \mathrm{~S}$ and $76 \mathrm{~S}$ were successfully prepared using a spray drying method. The characterizations show that as-prepared powders possessed a glassy structure, along with two morphologies of rough solid and porous sphere. The averaged particle sizes were measured as $6-9 \mu \mathrm{m}$, with surface areas range from $6-40 \mathrm{~m}^{2} / \mathrm{g}$. Finally, the bioactivity of all BG powders were confirmed by XRD with the formation of HA after immersion in the SBF for $12 \mathrm{~h}$.

Author Contributions: S.-J.S. conceived, designed and supervised the experiments; C.-W.H. performed the experiments; Y.-J.C. analyzed the data and wrote the original draft; N.-T.T. and M.-H.W. contributed analysis tools and reviewed the manuscript.

Funding: This research was funded by Ministry of Science and Technology of Taiwan (Grant numbers of MOST 105-2221-E-011-034, 106-2221-E-011-049 and 107-2218-E-009-003), and by Tokushima University, Japan, and National Taiwan University of Science and Technology, Taiwan (Grant number of TU-NTUST-106-01).

Acknowledgments: The authors thank Bo-Jiang Hong, Cheng-Yan, Tan and Ting-An Lin for helpful discussions.

Conflicts of Interest: The authors declare no conflict of interest.

\section{References}

1. Hench, L.L.; Splinter, R.J.; Allen, W.C.; Greenlee, T.K. Bonding mechanisms at the interface of ceramic prosthetic materials. J. Biomed. Mater. Res. 1971, 5, 117-141. [CrossRef]

2. Hench, L.L. Bioceramics: From concept to clinic. J. Am. Ceram. Soc. 1991, 74, 1487-1510. [CrossRef]

3. Hench, L.L. Bioactive ceramics: Theory and clinical applications. Bioceramics 1994, 7, 3-14.

4. Cao, W.; Hench, L.L. Bioactive materials. Ceram. Int. 1996, 22, 493-507. [CrossRef]

5. De Groot, K. Bioceramics of calcium phosphate. J. Clin. Eng. 1984, 9, 52. [CrossRef]

6. Vallet-Regí, M. Ceramics for medical applications. J. Chem. Soc. Dalton 2001, 0, 97-108. [CrossRef]

7. Kirsten, A.; Hausmann, A.; Weber, M.; Fischer, J.; Fischer, H. Bioactive and thermally compatible glass coating on zirconia dental implants. J. Dent. Res. 2015, 94, 297-303. [CrossRef] [PubMed]

8. Salinas, A.J.; Shruti, S.; Malavasi, G.; Menabue, L.; Vallet-Regí, M. Substitutions of cerium, gallium and zinc in ordered mesoporous bioactive glasses. Acta Biomater. 2011, 7, 3452-3458. [CrossRef]

9. Xia, W.; Chang, J. Well-ordered mesoporous bioactive glasses (MBG): A promising bioactive drug delivery system. J. Control. Release 2006, 110, 522-530. [CrossRef]

10. Christie, J.K.; Malik, J.; Tilocca, A. Bioactive glasses as potential radioisotope vectors for in situ cancer therapy: Investigating the structural effects of yttrium. Phys. Chem. Chem. Phys. 2011, 13, 17749-17755. [CrossRef]

11. Tilocca, A. Realistic models of bioactive glass radioisotope vectors in practical conditions: Structural effects of ion exchange. J. Phys. Chem. C 2015, 119, 27442-27448. [CrossRef] 
12. Hench, L.L. The story of bioglass. J. Mater. Sci. Mater. Med. 2006, 17, 967-978. [CrossRef] [PubMed]

13. Clark, A.E.; Pantano, C.G.; Hench, L.L. Auger spectroscopic analysis of bioglass corrosion films. J. Am. Ceram. Soc. 1976, 59, 37-39. [CrossRef]

14. Li, R.; Clark, A.; Hench, L.L. An investigation of bioactive glass powders by sol-gel processing. J. Appl. Biomater. 1991, 2, 231-239. [CrossRef] [PubMed]

15. Yan, X.; Yu, C.; Zhou, X.; Tang, J.; Zhao, D. Highly ordered mesoporous bioactive glasses with superior in vitro bone-forming bioactivities. Angew. Chem. Int. Ed. 2004, 43, 5980-5984. [CrossRef] [PubMed]

16. Shih, C.J.; Chen, H.T.; Huang, L.F.; Lu, P.S.; Chang, H.F.; Chang, I.L. Synthesis and in vitro bioactivity of mesoporous bioactive glass scaffolds. Mater. Sci. Eng. C 2010, 30, 657-663. [CrossRef]

17. Shih, S.-J.; Chou, Y.-J.; Chien, I.-C. One-step synthesis of bioactive glass by spray pyrolysis. J. Nanopart. Res. 2012, 14, 1-8. [CrossRef]

18. Messing, G.L.; Zhang, S.-C.; Jayanthi, G.V. Ceramic powder synthesis by spray pyrolysis. J. Am. Ceram. Soc. 1993, 76, 2707-2726. [CrossRef]

19. Chou, Y.-J.; Hong, B.-J.; Lin, Y.-C.; Wang, C.-Y.; Shih, S.-J. The correlation of pore size and bioactivity of spray-pyrolyzed mesoporous bioactive glasses. Materials 2017, 10, 488. [CrossRef]

20. Morhenn, V.B.; Lemperle, G.; Gallo, R.L. Phagocytosis of different particulate dermal filler substances by human macrophages and skin cells. Dermatol. Surg. 2002, 28, 484-490.

21. Tamjid, E.; Bagheri, R.; Vossoughi, M.; Simchi, A. Effect of particle size on the in vitro bioactivity, hydrophilicity and mechanical properties of bioactive glass-reinforced polycaprolactone composites. Mater. Sci. Eng. C 2011, 31, 1526-1533. [CrossRef]

22. Ghidelli, M.; Idrissi, H.; Gravier, S.; Blandin, J.-J.; Raskin, J.-P.; Schryvers, D.; Pardoen, T. Homogeneous flow and size dependent mechanical behavior in highly ductile Zr65Ni35 metallic glass films. Acta Mater. 2017, 131, 246-259. [CrossRef]

23. Vehring, R.; Foss, W.R.; Lechuga-Ballesteros, D. Particle formation in spray drying. J. Aerosol Sci. 2007, 38, 728-746. [CrossRef]

24. Nandiyanto, A.B.D.; Okuyama, K. Progress in developing spray-drying methods for the production of controlled morphology particles: From the nanometer to submicrometer size ranges. Adv. Powder Technol. 2011, 22, 1-19. [CrossRef]

25. Ostomel, T.A.; Shi, Q.; Tsung, C.-K.; Liang, H.; Stucky, G.D. Spherical bioactive glass with enhanced rates of hydroxyapatite deposition and hemostatic activity. Small 2006, 2, 1261-1265. [CrossRef]

26. Molino, G.; Bari, A.; Baino, F.; Fiorilli, S.; Vitale-Brovarone, C. Electrophoretic deposition of spray-dried Sr-containing mesoporous bioactive glass spheres on glass-ceramic scaffolds for bone tissue regeneration. J. Mater. Sci. 2017, 52, 9103-9114. [CrossRef]

27. Kokubo, T.; Ito, S.; Huang, Z.T.; Hayashi, T.; Sakka, S.; Kitsugi, T.; Yamamuro, T. Ca, P-rich layer formed on high-strength bioactive glass-ceramic A-W. J. Biomed. Mater. Res. 1990, 24, 331-343. [CrossRef]

28. Lintingre, E.; Lequeux, F.; Talini, L.; Tsapis, N. Control of particle morphology in the spray drying of colloidal suspensions. Soft Matter 2016, 12, 7435-7444. [CrossRef]

29. Vehring, R. Pharmaceutical particle engineering via spray drying. Pharm. Res. 2008, 25, 999-1022. [CrossRef]

30. Shih, S.-J.; Tzeng, W.-L. Manipulation of morphology of strontium titanate particles by spray pyrolysis. Powder Technol. 2014, 264, 291-297. [CrossRef]

31. Iskandar, F.; Gradon, L.; Okuyama, K. Control of the morphology of nanostructured particles prepared by the spray drying of a nanoparticle sol. J. Colloid Interface Sci. 2003, 265, 296-303. [CrossRef]

32. Shih, S.-J.; Chou, Y.-J.; Panjaitan, L.V.P. Synthesis and characterization of spray pyrolyzed mesoporous bioactive glass. Ceram. Int. 2013, 39, 8773-8779. [CrossRef]

33. Hench, L.L.; Wilson, J. An Introduction to Bioceramics; Word Scientific: Singapore, 1999.

(C) 2018 by the authors. Licensee MDPI, Basel, Switzerland. This article is an open access article distributed under the terms and conditions of the Creative Commons Attribution (CC BY) license (http://creativecommons.org/licenses/by/4.0/). 